\title{
Morphological Investigations of the Cervicothoracic Sympathetic System in the Horse (Equus ferrus caballus) in Egypt
}

\author{
Investigaciones Morfológicas del Sistema Simpático Cervicotorácico \\ en el Caballo (Equus ferrus caballus) en Egipto
}

Mohamed M. A. Abumandour* \& Fatma El-defrawy**

ABUMANDOUR, M. M.A. \& EL-DEFRAWY, F. Morphological investigations of the cervicothoracic sympathetic system in the horse (Equus ferrus caballus) in Egypt. Int. J. Morphol., 34(3):923-933, 2016.

SUMMARY: The current study was performed on twelve healthy adult horses (E. ferrus caballus) collected from Egypt were dissected to provide anatomical descriptions of bilaterally cervicothoracic sympathetic system macroscopically. On the left side, cervicothoracic sympathetic system is represented only by the caudal cervical ganglion, which presents on lateral surface of esophagus, cranial to the level of first rib. On right side, cervicothoracic sympathetic system is represented by the caudal and middle cervical ganglion. Caudal cervical ganglion was consisted of the fusion of eighth cervical and first three thoracic nerve ganglia. Caudal directed continuation branch of left ansa subclavia gave off a pericardial branch and then gave branch for ligamentum arteriosum. There are special sympathetic-parasympathetic communicating branches; on left side, there is only one branch that was present on lateral surface of esophagus, while on right side, there were four branches; two from caudal cervical ganglion and two from middle cervical ganglion. The most suitable site of ganglion blocks from both sides; needle was placed medioventrally between the articulation of first and second rib.

KEY WORDS: Horse; Caudal cervical ganglion; Sympathetic nerve; Subclavian; Sympathetic-parasympathetic communicating branches.

\section{INTRODUCTION}

In all mammals, the autonomic nervous systems consist of nerves and ganglions, that connect to the central nervous system on one side and to the viscera on the other side. The ganglia of the sympathetic chain in the cervical region are classically into three bilaterally ganglia; cranial, middle and caudal cervical ganglion (Rosse \& GaddumRosse, 1997; Fioretto et al., 2003; Gabella, 2004). Occasionally, there is a vertebral ganglion on the vertebral nerve, (Rosse \& Gaddum-Rosse).

The caudal cervical ganglion has been documented by many authors (Ozgel et al., 2009; Dyce et al., 2010; Evans \& de Lahunta, 2013). The caudal cervical ganglion was considered as an important center of sympathetic innervation of cervical region, neck and forelimbs (upper limb in human) (Phillips et al., 1986), so there is clinically importance of the cervicothoracic ganglion block (Schürmann et al., 2001; Ackerman \& Zhang, 2006; Marcer et al., 2011).

The aim of the present study was to describe the dimensions, shape and location of the ganglia of the cervicothoracic sympathetic system bilaterally of horse and nerve branches originating from these ganglia, in addition to its relationship with the adjacent structures. As there is a little available data about the cervicothoracic sympathetic system in horse, this study provides morphological basis for further research in comparative neuroanatomy and for future steps, for new techniques of block and surgical approach of cervicothoracic ganglion.

\section{MATERIAL AND METHOD}

Samples. Twelve healthy adult horses of both sexes (sexes and body weights were not recorded) were collected from the Behera Governate to the local dissecting hall in Faculty of Veterinary Medicine in Edfina, Behera Governate, Egypt, for student teaching purpose. This study followed the guidelines for the care and use of laboratory animals and the animal welfare and Ethics Committee of the Faculty of Veterinary Medicine, Alexandria University according the Egyptian laws, approved, in which adequate measures were taken to minimize pain or discomfort. 
Animal preparation . All horses had received intramuscular injection of acepromazine $(0.05 \mathrm{mg} / \mathrm{kg})$, and then followed after $10 \mathrm{~min}$ by intramuscular injection of xylazine $(0.2 \mathrm{mg} /$ $\mathrm{kg}$ of body weight $)$ and atropine $(0.04 \mathrm{mg} / \mathrm{kg})$. Then the horses were anesthetized by intravenous injection of ketamine (5.0 $\mathrm{mg} / \mathrm{kg}) 10$ minutes after sedative injection. They were injected intravenously with $10 \mathrm{~mm}$ of heparin (1,000 IU) to suppress coagulation. Then horses were well bled via a cannula placed in the common carotid artery and the cannula was subsequently used as an inflow port for injection of $10 \%$ formalin solution through the common carotid artery for fixation of these specimens. After specimens had been stored for two weeks, both sides of each specimen were carefully dissected to observe shape, location, and branches of the ganglia which share in the formation of the cervicothoracic sympathetic system bilaterally. The findings were photographed by means of a digital camera (Cannon IXY 325, Japan). The measurements were carried out by utilizing digital calipers, in which "ml" mean millimeter while "cm" mean centimeter. The Quantitative results were expressed as mean \pm SD.

\section{RESULTS}

\section{Morphological observations of the left side cervicothoracic sympathetic system.}

The left sided cervicothoracic sympathetic system is represented only by the caudal cervical ganglion. The caudal cervical ganglion is located on the lateral surface of esophagus, cranial to the level of distal portion of the proximal half of the first rib. The caudal margin of the indicated ganglion is located below the cranial margin of the first rib, while its lateral surface is covered with the medial scalenus muscle. The dorsal one third of this ganglion is overlapped the groove between the longus colli muscle and esophagus (Fig. 1).

The caudal cervical ganglion lies in the arterial triangular area, its apex caudally and its base cranially. This arterial triangular area is formed dorsally by the vertebral artery and ventrally by the left subclavian artery. The observed ganglion had an elongated satellite shape which compressed from its center (Fig. 1: G). On the left side of the median plane, the shapes and the measurements of the cervicothoracic ganglion are shown in Table I.

In ten examined horses, the caudal cervical ganglion was formed by the merger of the last (eighth) cervical (enter from the craniodorsal margin of the caudal cervical ganglion) (Figs. 1 and 2: a) and first three thoracic sympathetic ganglia (enter from the caudodorsal margin of ganglion) (Figs. 1, 2 and $3 \mathrm{~b}$ ) (Fig. 1: *). But in the remaining two examined horses, the caudal cervical ganglion was formed by the fusion of the last cervical and the first two thoracic sympathetic ganglia.

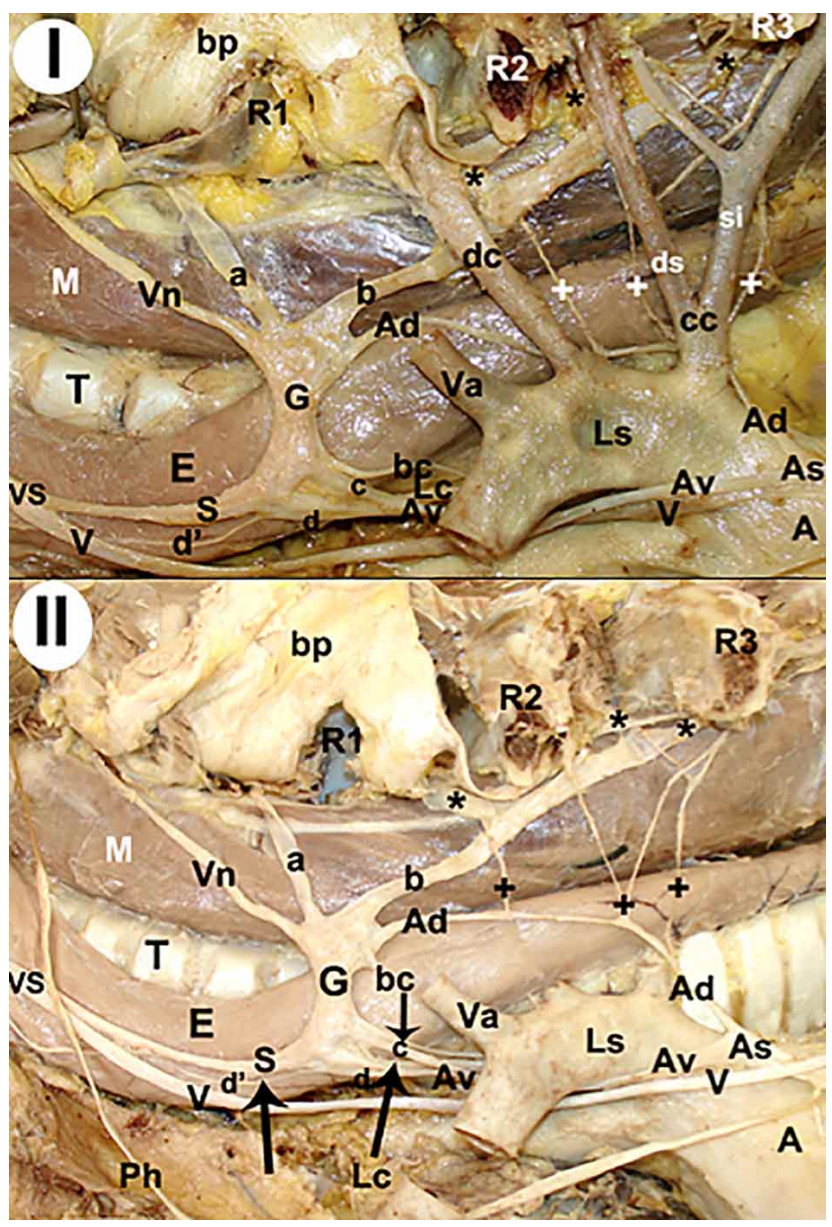

Fig. 1. Photographs of the lateral macroscopic appearance of the left caudal cervical ganglion after reflection of the brachial plexus: view (I) with the presence of the left subclavian artery and its branches while view (II) after removal of the left subclavian artery and its branches: A, brachiocephalic trunk; E, esophagus; G, caudal cervical ganglion; $\mathrm{M}$, longus colli muscle; T, trachea; $\mathrm{S}$, sympathetic nerve; V, vagus nerve; VS, vagosympathetic trunk; $\mathrm{Ph}$, phrenic nerve; Lc, left cardiac nerve; bc, brachiocephalic branch; c, dorsal branch of three branches forming ventral loop of ansa subclavia; d, ventral branch of three branches forming ventral loop of ansa subclavia; d', cranial continuation of the ventral branch of three branches forming ventral loop of ansa subclavia; R1, first rib; R2, second rib; R3, third rib; a, last cervical sympathetic nerve; $b$, common thoracic trunk of first, second, third thoracic sympathetic nerve (*); Ad, dorsal loop of ansa subclavia; Av, ventral loop of ansa subclavia; + , communicating branches of dorsal loop of ansa subclavia; bp, reflected brachial plexus; Ls, left subclavian artery; Va, vertebral artery; Vn. vertebral nerve; dc, deep cervical artery; cc, costocervical trunk artery; ds, dorsal scapular artery; si, supreme intercostal artery 
Table I. Shape and measurement values of the ganglion in both sides.

\begin{tabular}{|c|c|c|c|c|c|c|c|}
\hline \multirow{3}{*}{$\begin{array}{l}\text { Side } \\
\text { Left side }\end{array}$} & \multirow{4}{*}{$\begin{array}{l}\text { Ganglio n } \\
\text { CCG }\end{array}$} & \multirow{4}{*}{$\begin{array}{l}\text { Shape } \\
\text { Elongated satellite } \\
\text { shape and compressed } \\
\text { from its center }\end{array}$} & \multirow{4}{*}{$\begin{array}{c}\text { Length (c m) } \\
3.1 \pm 0.12\end{array}$} & \multicolumn{2}{|l|}{ Width (mm) } & \multicolumn{2}{|c|}{ Thickness (mm) } \\
\hline & & & & From middle part & $8.9 \pm 0.3$ & At the middle & $15 \pm 1.3$ \\
\hline & & & & From branched (do & $15 \pm 1.3$ & At apex & $3.1 \pm 0.14$ \\
\hline & & & & and base (ventral) part & & At base & $2.1 \pm 0.18$ \\
\hline \multirow[t]{2}{*}{ Right side } & CCG & Stellate & $1.3 \pm 0.12$ & At its middle part & $22 \pm 1.8$ & At its middle & $1.12 \pm 0.1$ \\
\hline & MCG & Star & $1 \pm 0.1$ & At its middle part & $10 \pm 1.3$ & At its middle & $1.12 \pm 0.1$ \\
\hline
\end{tabular}

$\mathrm{CCG}=$ Caudal cervical ganglion, $\mathrm{MCG}=$ Middle cervical ganglion .

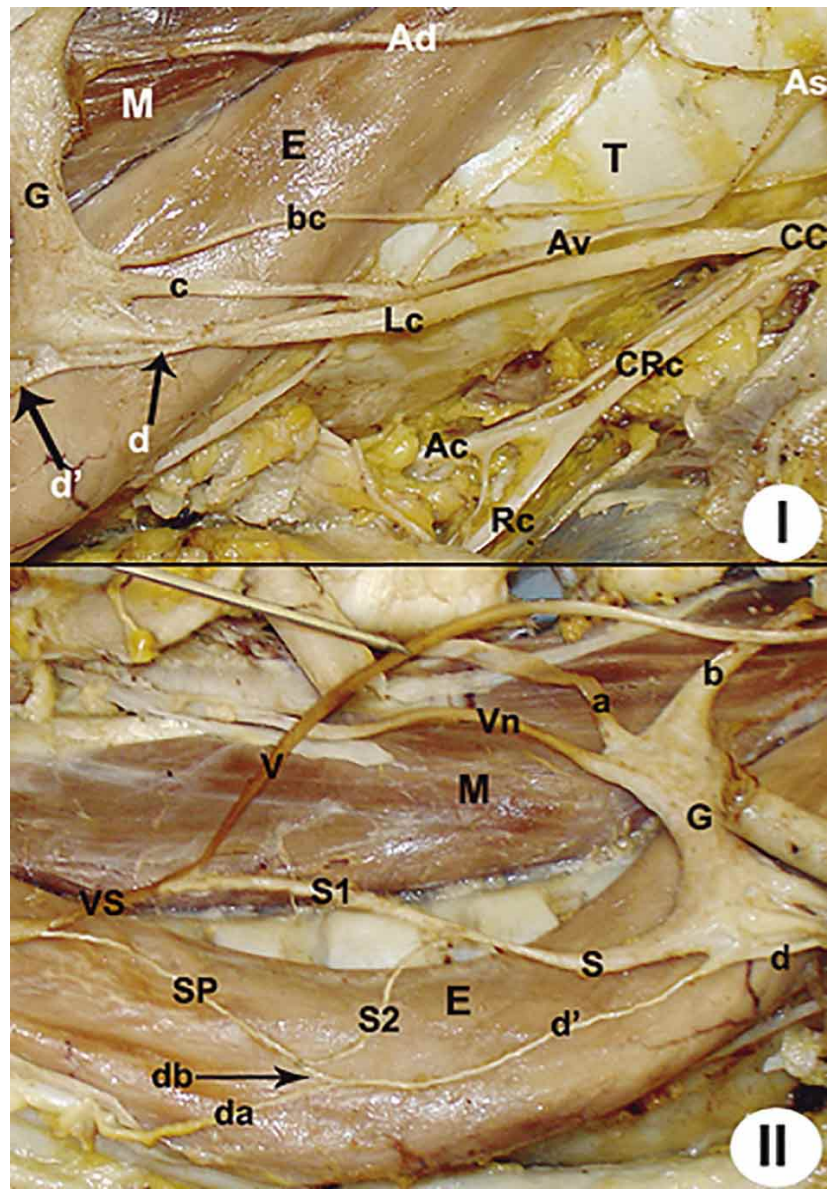

Fig. 2. Photographs of the lateral appearance of the left caudal cervical ganglion: view (I) to show the caudal directed branches of ganglion while view (II) to show the cranial directed branches of ganglion: E, esophagus; G, caudal cervical ganglion; M, longus colli muscle; T, trachea; S, sympathetic nerve; V, vagus nerve; VS, vagosympathetic trunk; Lc, left cardiac nerve; Rc, right cardiac nerve; CRc, common right cardiac nerve; cc, common cardiac nerve; bc, brachiocephalic branch; c, dorsal branch of three branches forming ventral loop of ansa subclavia; $d$, ventral branch of three branches forming ventral loop of ansa subclavia; d', cranial continuation of the ventral branch of three branches forming ventral loop of ansa subclavia; da, branch of common carotid artery and carotid sheath; $d b$, continuation of d'; S1, main sympathetic nerve; S2, secondary branch of sympathetic nerve; SP, sympatheticparasympathetic communicants branch; Ad, dorsal loop of left ansa subclavia; Av, ventral loop of left ansa subclavia; As; left ansa subclavia; Ac, caudal loop of right ansa subclavia.

\section{Branches of the caudal cervical ganglion}

1. The vertebral nerve. The vertebral nerve (Fig. 1: Vn) had its origin from the craniodorsal angle of caudal cervical ganglion. The vertebral nerve coursed in the craniodorsal direction on the lateral surface of longus colli muscle, then it passed along with the vertebral artery (Fig. 1: Va) and vertebral vein under the transverse process of the seventh cervical vertebrae then enter through transverse foramen of the sixth cervical vertebrae.

2. The ansa subclavian nerve. In all examined horses, the nerves which originated from caudal cervical ganglion and surrounded the left subclavian artery were known as ansa subclavia (Figs. 1 and 2: As). Ansa subclavian consisted of two nerves continued caudally as dorsal and ventral loop.

The ventral loop (Fig. 1 and 2 and 3: Av) had its origin from the caudoventral angle of the ganglion by three separated branches; the dorsal branch $(2.5 \pm 0.13 \mathrm{~mm}$ in width) is the thicker one (Figs. 1and 2: c) while the other two branches (middle and ventral) are similar to each other in width (1.2 $\pm 0.5 \mathrm{~mm}$ in width) (Figs. 1 and 2: d), in which between the middle and ventral branches, the left cardiac nerve (Figs.1, 2: Lc) was originated from the ganglion. These three branches (dorsal thick one, and two thinner) were directed caudoventrally and then fused after their origin by $2.7 \pm 0.17 \mathrm{~cm}$ to form the common trunk of the ventral loop ( $5 \pm 0.14 \mathrm{~mm}$ in width), which coursed with the vagus nerve on the medial aspect of the curved part of the left subclavian artery. This common trunk of the ventral loop began to cross the ventral aspect of the left subclavian artery to join the dorsal loop on the lateral surface of left subclavian artery to form left ansa subclavia (Fig. 1: As). The course of common nerve trunk of the ventral loop from its origin is parallel to the course of vagus nerve (Figs.1 and 3: V).

The dorsal loop ( $3 \pm 0.2 \mathrm{~mm}$ in width) of the ansa subclavia nerve had its origin from the caudodorsal angle of ganglion below the level of first rib, and then directed caudally at the lateral surface of the esophagus and at the medial surface of the vertebral artery, deep cervical artery 
and costocervical trunk. And then it deviated ventrally at the level of cranial margin of the third rib and from caudal margin of the costocervical trunk, and joined with the ventral loop at the lateral surface of the left subclavian artery. After this merger, there was a branch that continued directly caudal and this branch was $6 \pm 0.16 \mathrm{~mm}$ in width (Fig. 3: DAs).

The dorsal loop gave three communicating branches (Fig. 1: +); the cranial one had its origin at the level of the first intercostal space and it was communicated with the first thoracic sympathetic nerve. While the middle one had its origin at the level of the caudal margin of the second intercostal space and then it gave two branches after $3 \pm 0.2$ $\mathrm{mm}$ from its origin. The caudal one originated at the level of the third intercostal space and then it gave two branches after $4 \pm 0.17 \mathrm{~cm}$ from its origin. It was observed that all branches separated from the dorsal loop were connected to sympathetic trunk.

The caudal directed continuation branch of the ansa subclavia (Fig. 3: DAs) was passed caudally to reach the pericardium at the level of the third intercostal space, then before penetrating the pericardium by $1.1 \pm 0.15 \mathrm{~cm}$ and after its formation by $2 \pm 0.11 \mathrm{~cm}$ gave off one small pericardial branch to the pericardium (Fig. 3: Pr), then the continuated branch of the ansa subclavia penetrated the pericardium and gave two branches after its origin by $4.3 \pm 0.22 \mathrm{~cm}$; one branch for the ligamentum arteriosum and the other branch is the ventral cardiac branch.

The branch for ligamentum arteriosum (Fig. 3: ga) was branched after its origin by $2.1 \pm 0.16 \mathrm{~cm}$ to give four small branches; three for ligamentum arteriosum and the most dorsal one to the aortic arch.

The ventral cardiac branch of the caudal directed continuation of the left ansa subclavia (Fig. 1: vb) was originated at the level of the origin of the brachiocephalic trunk, then directed ventrally, and then after its origin by $4 \pm 0.2 \mathrm{~cm}$ and at the caudal margin of the left auricle and cranial margin of the aortic arch gave three branches; cranial, middle and caudal branches. The cranial one is the long one $(8 \pm 0.2 \mathrm{~cm}$ in length) then impeded in the cardiac musculature at the conus arteriosus while another two branches entered under the left atrium.

3. The sympathetic nerve. Sympathetic nerve (Figs. 1 and 2: S) had its origin from the cranioventral angle of the ganglion then coursed cranioventrally on the lateral surface of the esophagus. This nerve accompanying with the vagus nerve in the cervical region and named vagosympathetic trunk and covered with a sheath after $4 \pm 0.2 \mathrm{~cm}$ from its origin (Figs. 1 and 2: VS).
4. The left cardiac nerve. Left cardiac nerve (Figs. 1 and 2: Lc) had its origin from the caudoventral angle of the cervicothoracic ganglion (without sharing in the formation of the ansa subclavia). Then it was coursed caudoventrally under the left subclavian artery to unite with the common right cardiac nerve (Fig. 2: CRc) after $8.8 \pm 0.19 \mathrm{~cm}$ from its origin near the lateral surface of the trachea to form the common cardiac nerve (Fig. 2: CC) to share in the formation of the cardiac plexus.

5. The nerve to the brachiocephalic trunk. A small branch to the brachiocephalic trunk (Figs. 1, 2 and 3: bc) was originated from the ventral part of the caudal margin of the cervicothoracic ganglion and dorsal to the origin of the left cardiac nerve by $1 \pm 0.12 \mathrm{~mm}$ (without sharing in the formation of the ansa subclavian), then coursed caudoventrally parallel to the left cardiac nerve and attached to it with common sheath after its origin by $4 \pm 0.15 \mathrm{~cm}$ then separated from the common sheath to supply the brachiocephalic trunk (Fig. 1: A).

6. The rami communicates. In all examined horses, rami communicates were originated from the cervicothoracic ganglion or its branches to join the brachial plexus. Eight of examined horses, had one ramus communicating from the cervicothoracic ganglion, whereas two horses, had one ramus communicating from vertebral nerve, another two horses from the dorsal loop of ansa subclavia.

\section{The sympathetic-parasympathetic communicating} branch. There is a sympathetic-parasympathetic communicating branch located on the lateral surface of the esophagus. There is a cranial continuation of the ventral branch of the three branches (sharing in the formation of the ventral loop of ansa subclavian) originated from the caudoventral angle of the caudal cervical ganglion (Figs. 1 and 2: d'). during the course of this cranial continuated branch, it gave a small branch to the left common carotid artery and carotid sheath (Fig. 2: da) after its origin by $4.5 \pm 0.16 \mathrm{~cm}$ while the main branch (Fig. 2: db) is unit with a branch originated from the sympathetic nerve (Fig. 2: S2) after its origin by $6.5 \pm 0.15 \mathrm{~cm}$ to form a sympatheticparasympathetic branch (Fig. 2: SP) to the vagus nerve.

\section{Anatomical observations of the cervicothoracic ganglion on the right side}

In all examined horses; the right sided cervicothoracic sympathetic system is represented by two ganglia; the caudal and middle cervical ganglion. The caudal cervical ganglion (Fig. 4: G) was situated at the level of first rib, in which the dorsal half of the ganglion lies on the ventrolateral surface of the longus colli muscle, while the ventral half lies 


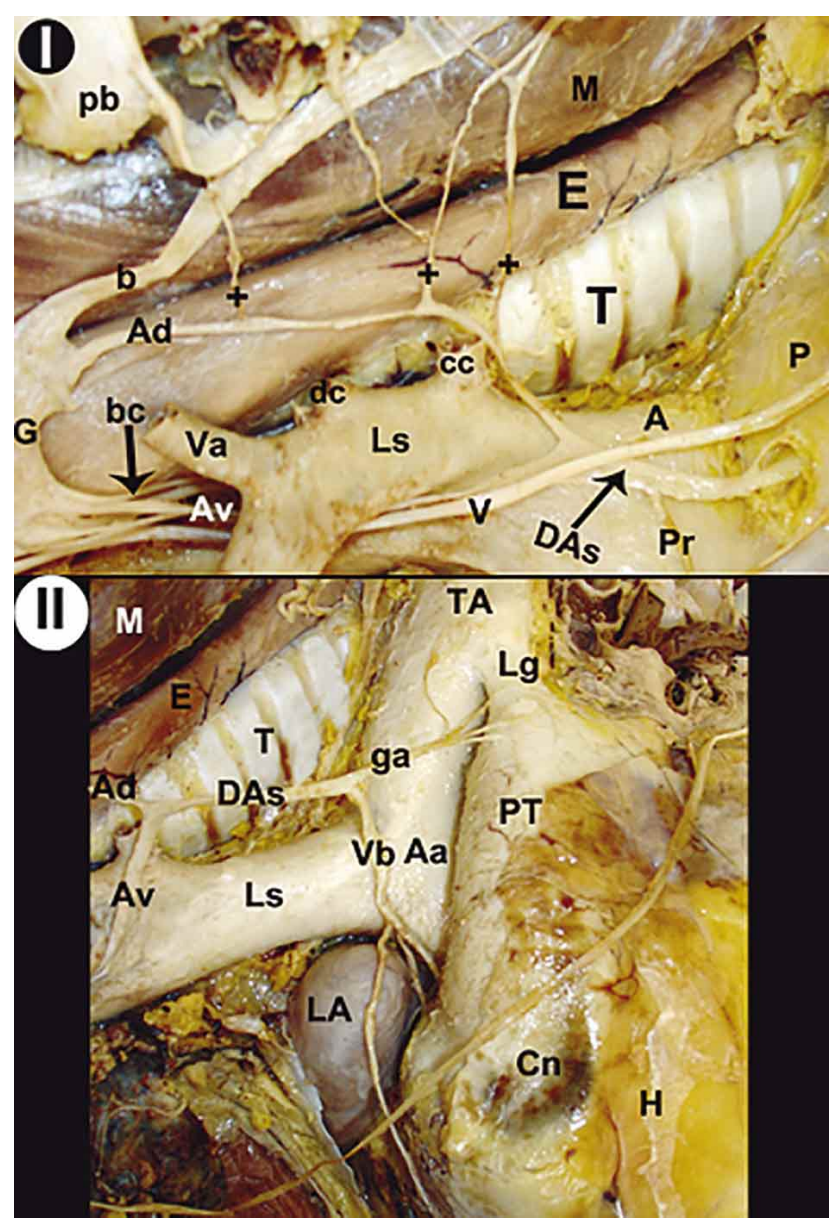

Fig. 3. Photographs of the lateral appearance of the left caudal cervical ganglion: views (I and II) to show the caudal directed branches of ganglion: A, brachiocephalic trunk; E, esophagus; G, caudal cervical ganglion; M, longus colli muscle; T, trachea; V, vagus nerve; P, pericardium; Pr, pericardial branch; bc, brachiocephalic branch; b, common thoracic trunk of first, second, third thoracic sympathetic nerve; Ad, dorsal loop of ansa subclavia; Av, ventral loop of ansa subclavia; Ls, left subclavian artery; Va, vertebral artery; dc, deep cervical artery; cc, costocervical trunk artery; pb, reflected brachial plexus; DAs, caudal continuation of left ansa subclavia; Lg, ligamentum arteriosus; ga, branches for ligamentum arteriosus; vb, ventral cardiac branch of caudal continuation of left ansa subclavia; PT, pulmonary trunk; Cn, conus arteriosus; H, heart; Aa, aortic arch; TA, thoracic aorta; LA, left atrium; +, communicating branches of dorsal loop of ansa subclavian.

on the groove between the longus colli muscle and trachea. The caudal part of the ganglion lies craniomedial to the origin of the deep cervical artery (Fig. 4: dc), it becomes clear that this ganglion lies in the arterial triangular area, its apex ventrally and its base dorsally. This arterial triangular area was formed cranially by the vertebral artery and caudally

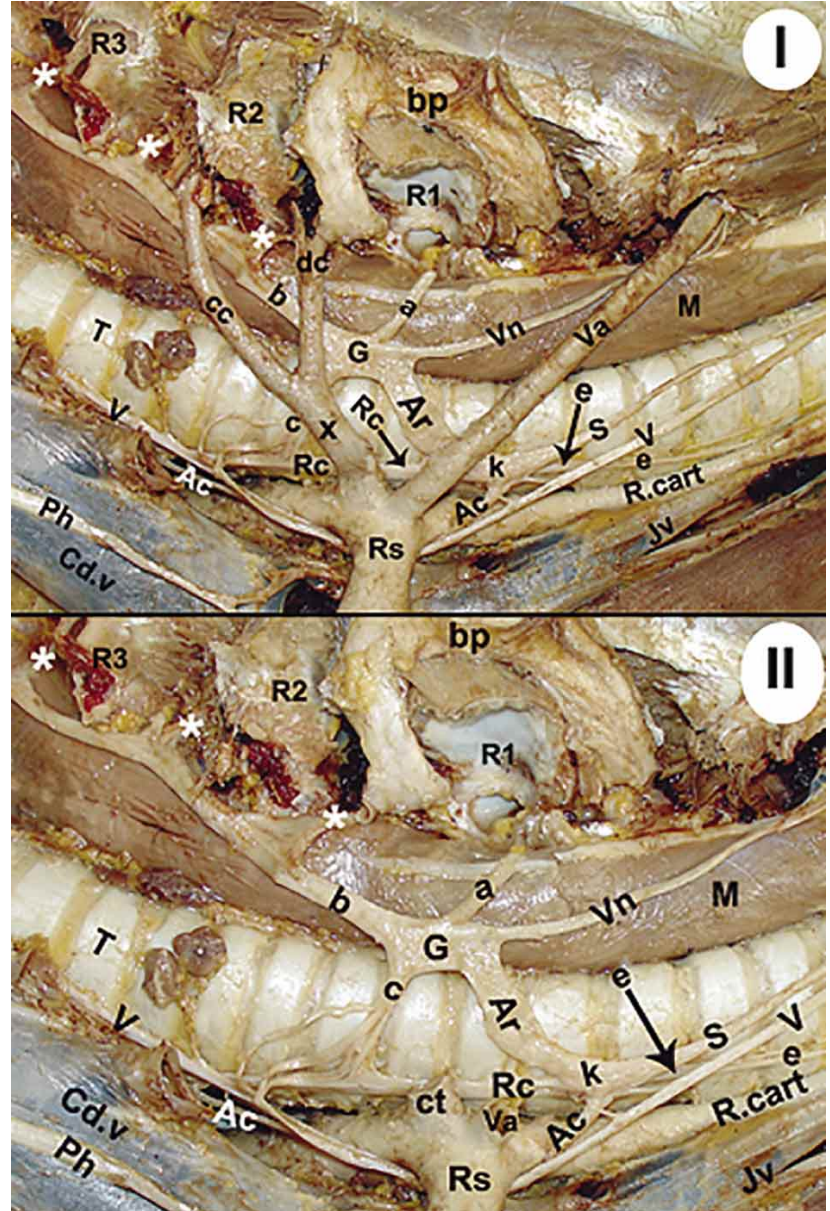

Fig. 4. Photographs of the lateral view of the right caudal and middle cervical ganglion after reflection of the brachial plexus: view (I) with the presence of the right subclavian artery and its branches while view (II) after removal of the right subclavian artery and its branches: E, esophagus; G, caudal cervical ganglion; k, middle cervical ganglion; $\mathrm{M}$, longus colli muscle ; T, trachea; $\mathrm{S}$, sympathetic nerve; $\mathrm{V}$, vagus nerve; $\mathrm{Ph}$, phrenic nerve; R.cart, right carotid artery; Rc, right caudal cardiac nerve of middle cervical ganglion; R1, first rib; R2, second rib; R3, third rib; a, last cervical sympathetic nerve; $b$, common thoracic trunk of first, second, third thoracic sympathetic nerves $(*)$; c, right caudoventral cardiac nerve of caudal cervical ganglion; e, tracheal nerve; Ar, cranial loop of ansa subclavia; Ac, caudal loop of ansa subclavia; bp, reflected brachial plexus; Rs, right subclavian artery; Va, vertebral artery; Vn. Vertebral nerve; dc, deep cervical artery; cc, costocervical artery; $\mathrm{x}$, common trunk of dc and cc; CT, common trunk of deep cervical and costocervical artery; Jv, right jugular vein; cd.v., caudal venea cava.

by the deep cervical artery (Fig. 4: Va, dc). The lateral surface of the ganglion was covered with the medial scalenus muscle as in left side. The shape of ganglion was stellate. On the right side of the median plane, the shapes and the measurements of the caudal cervical ganglion were shown in Table I. 
Middle cervical ganglion (Figs. 4 and 5: k) was situated cranioventral to the caudal cervical ganglion and proceeding it by $1.7 \pm 0.18 \mathrm{~cm}$ at the ventrolateral surface of the trachea and parallel to the vagus nerve which situated ventral to this ganglion. The middle cervical ganglion communicated with the caudal cervical ganglion only by one main nerve trunk (which considered as the cranial loop of the ansa subclavia).

Middle cervical ganglion lies in the arterial triangular area (apex caudally and base cranially). This arterial triangular area was formed by the vertebral artery dorsally and the right common carotid artery ventrally (Fig. 4: Va, R.cart). The caudal part of the ganglion lies medial to the vertebral artery after $2 \pm 0.2 \mathrm{~cm}$ from its origin. The shape of ganglion was star. On the right side of the median plane, the shapes and the measurements of the middle cervical ganglion are shown in Table I.

Caudal cervical ganglion was formed by the merger of the last (eighth) cervical (enter from the dorsal margin of the ganglion) (Fig. 4: a) and common sympathetic nerve trunk (enter from the caudodorsal margin of ganglion) (Fig. $4:$ b) of the first three thoracic sympathetic ganglia in all examined horses (Fig. 4: *), except in two cadavers; The ganglion was formed by the union of last cervical and common sympathetic trunk of first and second thoracic sympathetic ganglia.

\section{A) Branches of the caudal cervical ganglion}

1. The vertebral nerve. Vertebral nerve (Fig. 4: Vn) had its origin at the craniodorsal angle of the caudal cervical ganglion. As in left side, the nerve was coursed after its origin in the craniodorsal direction on the lateral surface of the longus colli muscle and medial to the medial scalenus muscle to reach the vertebral artery cranial to first rib by $3 \pm 0.1 \mathrm{~cm}$ then pass together under the transverse process of seventh cervical vertebra then enters the transverse canal through the transverse foramen of sixth cervical vertebra.

2. The cranial loop of ansa subclavian nerve. Ansa subclavia was formed by two loops; the cranial and caudal loop. The caudal loop (Fig. 4: Ac) had its origin from the middle cervical ganglion while the cranial loop (Fig. 4: Ar) of $3.5 \pm 0.18 \mathrm{~cm}$ in length and $9 \pm 0.12 \mathrm{~mm}$ in width, was originated from the cranioventral angle of the caudal cervical ganglion, then directed cranioventrally from the lateral to ventral surface of the trachea to enter from the caudodorsal angle of the middle cervical ganglion.

3. The right caudoventral cardiac nerve. On the lateral surface of trachea, from the caudoventral angle of the cau- dal cervical ganglion, the right caudoventral cardiac nerve (Figs. 4 and 5: c) of $3.5 \pm 0.16 \mathrm{~mm}$ in width was slightly directed caudoventrally then branched after its origin by $1.1 \pm 0.1 \mathrm{~cm}$ into 3 branches; cranial, middle and caudal branch. The cranial one (Fig. 5: cr) was the shorter one $(1.5 \pm 0.15 \mathrm{~cm}$ in length and $1.5 \pm 0.09 \mathrm{~mm}$ inwidth) which communicated with the right caudal cardiac nerve (Fig. 5: Rc). The middle one (Fig. $5: \mathrm{cm})$ was the wider $(2 \pm 0.14$ $\mathrm{mm}$ in width); which directed caudoventrally and branched after its origin by $1.8 \pm 0.1 \mathrm{~cm}$ to give the secondary branch (Fig. 5: cm1) to communicate with the right caudal cardiac nerve, while the main branch coursed caudoventrally to join with another branch from the right caudal cardiac nerve (Fig. 5: Rc1) to form the first sympathetic-parasympathetic communicating branch of the caudal cervical ganglion (Fig. 5: SP1) to communicate with the vagus nerve (Fig. 5: V). The caudal longer one is the second sympatheticparasympathetic communicating branch of the caudal cervical ganglion (Fig. 5: SP2), which was directed ventrally to communicate with the vagus nerve after the previous sympathetic-parasympathetic communicating branch by $1 \pm 0.08 \mathrm{~cm}$.

\section{B) Branches of the middle cervical ganglion}

1. The sympathetic nerve. Sympathetic nerve (Figs. 4 and 5: S) had its origin from the craniodorsal angle of the middle cervical ganglion then coursed craniodorsally on the lateral surface of trachea to form the vagosympathetic trunk with the vagus nerve (Fig. 4: V) at the distance of $5.5 \pm 0.38 \mathrm{~cm}$ from its origin and after $6.5 \pm 0.36 \mathrm{~cm}$ from the cranial margin of the first rib and extend toward the head on the lateral surface of the trachea.

2. The tracheal nerve. Tracheal nerve (Figs. 4 and 5: e) had its origin from the middle cervical ganglion by two branches; the main large branch $(2 \pm 0.1 \mathrm{~mm}$ in width) originated from the cranial margin of the middle cervical ganglion while the other small branch $(1 \pm 0.1 \mathrm{~mm}$ in width) originated from the craniodorsal margin of the middle cervical ganglion. After that, the two branches united to form the tracheal nerve, in which the first $1 \pm 0.1 \mathrm{~cm}$ from the tracheal nerve was covered the initial part of the sympathetic nerve (Figs. 4 and 5: S, e).

Tracheal nerve was branched into the lateral and the medial branch after its origin by $2 \pm 0.12 \mathrm{~cm}$, then those two branches pass cranially on the ventral surface of the trachea under the right common carotid artery, in which the lateral one passes under the right common carotid artery after its origin by $5.5 \pm 0.35 \mathrm{~cm}$ while the medial one passes under the right common carotid artery after its origin by $3 \pm 0.24 \mathrm{~cm}$. 


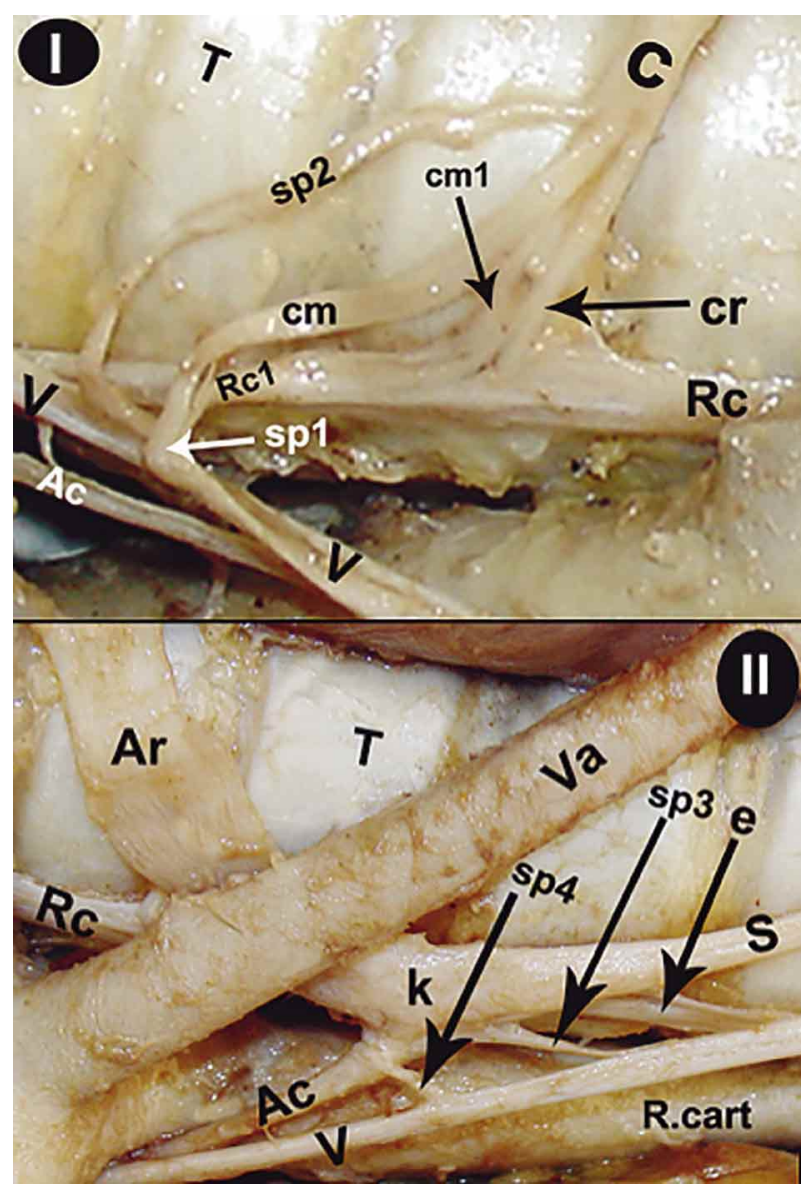

Fig. 5. Photographs of the right ventrolateral surface of the trachea: view (I) to clarify the branches of the ventral branch of the caudal cervical ganglion and view (II) to clarify the branches of the middle cervical ganglion: $\mathrm{k}$, middle cervical ganglion; $\mathrm{T}$, trachea; $\mathrm{S}$, sympathetic nerve; $\mathrm{V}$, vagus nerve; R.cart, right carotid artery; Rc, right cardiac nerve; Rc1, secondary branch of Rc; c, ventral nerve of the caudal cervical ganglion; cr, cranial branch of $\mathrm{c} ; \mathrm{cm}$, middle branch of $\mathrm{c} ; \mathrm{cm} 1$, secondary branch of cm; e, tracheal nerve; Ar, cranial loop of ansa subclavia; Ac, caudal loop of ansa subclavia; Va, a. vertebralis; SP1, first sympatheticparasympathetic communicants; SP2, second sympatheticparasympathetic communicants; SP3, third sympathetic-parasympathetic communicants; SP4, fourth sympathetic-parasympathetic communicants.

3. The first sympathetic-parasympathetic communicating branch of the middle cervical ganglion. This branch (Fig. 5: SP3) had its origin from the ventral margin of the ganglion and directed cranioventrally to communicate with the vagus nerve.

4. The caudal loop of ansa subclavian. The caudal loop of the ansa subclavian ( $3 \pm 0.12 \mathrm{~mm}$ in width) (Figs. 4, 5 and 6: Ac) had its origin from the cranioventral margin of the middle cervical ganglion and directed caudoventrally, and then after its origin by $2 \pm 0.01 \mathrm{~mm}$, this loop gives the second sympathetic-parasympathetic communicating branch of the middle cervical ganglion (Fig. 5: SP4) to the vagus nerve, in

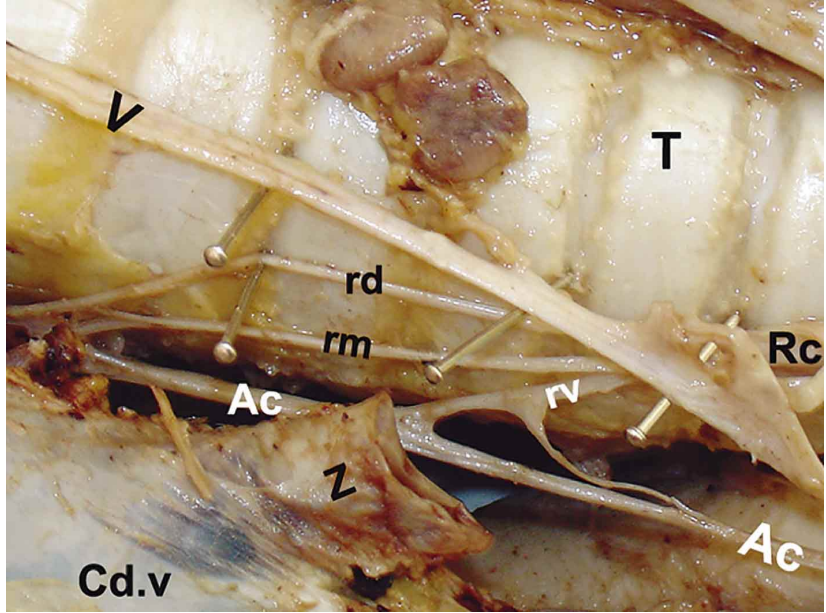

Fig. 6. Photograph of the right ventrolateral surface of the trachea to demonstrate the branches of the ventral branch of the right cardiac nerve (Rc): T, trachea; $S$, sympathetic nerve; Rc, right cardiac nerve; Ac, caudal loop of ansa subclavia; $\mathrm{V}$, vagus nerve; rd, dorsal branch of $\mathrm{Rc}$; rm, middle branch of Rc; rv, ventral branch of Rc; Cd.v, caudal venea cava; $Z$, right azygus vein.

which the distance between those two sympatheticparasympathetic communicating branch reach to $1.8 \pm 0.21 \mathrm{~cm}$.

Then after that the caudal loop of ansa subclavian coursed under the right subclavian artery (Fig. 4: Rs) with the vagus nerve (Fig. 4: V), then this loop directed caudally on the ventral surface of trachea. Then during the course of the caudal loop of ansa subclavian (after its origin by $6.5 \pm 0.34$ $\mathrm{cm}$ ), it received the communicating branches from the ventral branch of the right caudal cardiac nerve (Fig. 6: rv).

5. The right caudal cardiac nerve. Right caudal cardiac nerve $(4 \pm 0.08 \mathrm{~mm}$ in width) had its origin from the caudoventral angle of the middle cervical ganglion (Figs. 4, 5 and 6: Rc) and directed caudally on the ventrolateral surface of trachea, below the level of caudal margin of the first rib. The right caudal cardiac nerve was originated directly under the caudal margin of the vertebral artery (Figs. 4 and 5: Va) and after coursing by $0.5 \pm 0.11 \mathrm{~cm}$ passes below the medial surface of the common trunk of deep cervical and costocervical arteries (Fig. 4: $\mathrm{x}$ ), then communicated with the cranial branch of the right caudoventral cardiac nerve (Fig. 5: cr) after its origin by $3.8 \pm 0.2 \mathrm{~cm}$.

After its origin by $5.3 \pm 0.24 \mathrm{~cm}$, it was divided into 3 branches on the ventral surface of trachea; dorsal, middle and ventral. The dorsal $(1 \pm 0.04 \mathrm{~mm}$ in width) was directed caudally to join with the middle one after $3.7 \pm 0.23 \mathrm{~cm}$ from its origin (Fig. 4: rd), while the middle one $(1 \pm 0.02 \mathrm{~mm}$ in width) (Fig. 4: rm) was joined with the dorsal one after its origin by $4 \pm 0.42 \mathrm{~cm}$ then this common nerve trunk united to 
the caudal loop of ansa subclavian after $2 \pm 0.19 \mathrm{~cm}$ from its formation. The ventral one $(1 \pm 0.15 \mathrm{~mm}$ in width) was the shorter one (Fig. 4: rv) which directed caudoventrally then divided into two branches after its origin by $1.3 \pm 0.24 \mathrm{~cm}$ to communicate with the caudal loop of ansa subclavia, in which one branch proceeding to other by $2.3 \pm 0.26 \mathrm{~cm}$ in the communication.

Then, the right caudal cardiac nerve with its communicating branches merged to form the cardiac plexus on the ventral surface of trachea, dorsal to the base of the heart and dorsal to the origin of the cranial vena cava, then the right caudal cardiac nerve united with the caudal loop of ansa subclavian to form the common right cardiac nerve (Fig.
2: Ac, Rca and CRc), which communicated with the left cardiac nerve on the left side ventral to trachea to form the common cardiac nerve (Fig. 2: CC).

The measurements of the all nerves originated from the ganglia of both sides were recorded in Tables II and III.

\section{Clinical bilaterally approach to the caudal cervical ganglion in horse}

To produce the caudal cervical ganglion blocks in horse from right and left side, the most suitable site; the needle was placed medioventrally between the articulation of first and second rib.

Table II. The measurement values of the nerves in both sides.

\begin{tabular}{|c|c|c|c|c|}
\hline Nerve & Meas & ment (mm) & Left side & Right side \\
\hline Eighth cervical nerve & Width & At its entrance from the craniodorsal border of gangli on & $3 \pm 0.1$ & $4 \pm 0.14$ \\
\hline First three thoracic sympathetic ganglia & Width & At its entrance from the caudodorsal border of ganglion & $9.1 \pm 0.15$ & $7 \pm 0.17$ \\
\hline Vertebral nerve & Width & At its origin from ganglion & $3 \pm 0.0$ & $3 \pm 0.13$ \\
\hline Branch for ligamentum arteriosum & Width & & $2 \pm 0.14$ & Not present \\
\hline Sympathetic nerve & Width & At its origin & $5 \pm 0.2$ & $3 \pm 0.12$ \\
\hline Cardiac nerve & Width & & $3 \pm 0.2$ & $3.5 \pm 0.16$ \\
\hline
\end{tabular}

Table III. The measurement values of the sympathetic-parasympathetic communicating branches.

\begin{tabular}{lllcc}
\hline Side & Nerve & & $\begin{array}{c}\text { Width at their } \\
\text { origin (mm) }\end{array}$ & $\begin{array}{c}\text { Length } \\
\text { (cm) }\end{array}$ \\
\hline Left & $\begin{array}{l}\text { A sympathetic-parasympathetic branch } \\
\text { First sympathetic-parasympathetic communicating branch of } \\
\text { caudal cervical ganglion }\end{array}$ & $0.5 \pm 0.01$ & $3.5 \pm 0.16$ \\
& $\begin{array}{l}\text { Second sympathetic-parasympathetic communicating branch of } \\
\text { caudal cervical ganglion }\end{array}$ & $2.5 \pm 0.14$ & $1.5 \pm 0.1$ & $1.5 \pm 0.12$ \\
Right & $\begin{array}{l}\text { First sympathetic-parasympathetic communicating branch of } \\
\text { middle cervical ganglion } \\
\text { Second sympathetic-parasympathetic communicating branch of } \\
\text { middle cervical }\end{array}$ & $1.5 \pm 0.06$ & $1.8 \pm 0.08$ \\
& & $1 \pm 0.01$ & $0.6 \pm 0.017$ \\
\hline
\end{tabular}

\section{DISCUSSION}

Many anatomical data reported that the caudal cervical ganglion was situated bilaterally at the level of first intercostal space (Pather et al., 2006; Ozgel et al.; Evans \& de Lahunta, 2013), but König \& Liebich (2007) noted that the cervicothoracic ganglion lies medial to the first rib, while Ozgel et al. reported that there is some variation in the position of the caudal cervical ganglion; in four donkey the location of ganglion at the first intercostal space bilaterally, while in one donkey, this ganglion was located at the level of second intercostal space on left side, while on right side was situated in a wide area, from the first and second intercostal spaces. In the present study, the left caudal cervical ganglion was situated cranial to the level of the first rib, in which the caudal margin of the ganglion was situated below the cranial margin of the first rib, while the right caudal cervical ganglion was situated at the level of the first rib and the middle cervical ganglion was situated cranioventral to the caudal cervical ganglion and at the ventrolateral margin of trachea. Hogan \& Erickson (1992) and Raj (1996) noted that the stellate ganglion lies in the front of the first rib and extended to the space between bodies of the seventh cervical vertebrae and the first thoracic vertebrae. 
There is some variations in the position of a cervicothoracic ganglia as reported in many published data. A cervicothoracic ganglion was located on the lateral surface of the longus colli muscle (Phillips et al.; Ozgel et al.; Evans \& de Lahunta, 2013), but in the present investigation, the left caudal cervical ganglion was situated on the lateral surface of the esophagus and the dorsal margin of ganglion overlapped the groove between longus colli muscle and esophagus, while on right side, the dorsal half of the caudal cervical ganglion was located on the ventrolateral surface of the longus colli muscle, while the ventral half hanged on the groove between the longus colli muscle and trachea. In cat, the right stellate ganglion had its location over the base of first rib, while the left stellate ganglion was located on the neck of first and second rib (Phillips et al.).

Various shapes of the caudal cervical ganglion have been reported in many literatures (Hogan \& Erickson; Kalsey et al., 2000; Pather et al.; Marcer et al.); in donkeys (Ozgel et al.), noted that there are five different shapes; star, spindlelike (fusiform), lunate, irregular and oval shapes, while Pather et al. observed three different shapes; spindle, dumbbell, and an inverted "L" shape, but Phillips et al. noted that the right middle cervical ganglion was spindle-shaped. In this investigation, the left caudal cervical ganglion was stellate in shape and compressed from its center, while the right caudal cervical ganglion was stellate and middle cervical ganglion was star.

Interestingly, in the present study, there is a relation between position of the caudal cervical ganglion with the head of first rib and important arterial vessels in this region, in which the right caudal cervical ganglion lies under the first rib in arterial triangular area, which bounded by; the vertebral artery cranially and the deep cervical artery caudally and head of first rib dorsally, while the right middle cervical ganglion lies in the arterial triangular area bounded by; the vertebral artery dorsally and the right common carotid artery ventrally. Moreover, the left caudal cervical ganglion was located in the arterial triangular area, which bounded by; the vertebral artery dorsally and the left subclavian artery ventrally. The presence of this triangular area was reported by Katritsis et al. (1981).

Many previous published anatomical articles described that, there are many morphological differences in the formation of the caudal cervical ganglion between different animals; in which the caudal cervical ganglion formed by the coalescence of the last cervical and first thoracic sympathetic nerves on both sides (Dursun, 2000; Ozgel et al.). In addition, Ozgel et al., observed that the caudal cervical ganglion formed bilaterally by the coalescence of the last cervical and the first and second thoracic sympathetic nerves in two donkeys, which agrees with Singh et al. (2005). In the present study, the bilaterally caudal cervical ganglion was formed by the coalescence of the last cervical and first three thoracic sympathetic nerves, this result agrees with Evans \& de Lahunta (2010) in one cadaver on the right side, and also Chung et al. (2002) and Evans \& de Lahunta (2013) noted that the first four thoracic nerves may include in the formation of this ganglion. In human, the cervicothoracic ganglion was formed by the coalescence of the last two cervical, and generally first thoracic nerve (Pather et al.) and sometimes second (Kalsey et al.) or additionally third and fourth thoracic sympathetic nerves (Arınc1 \& Elhan, 1995).

The vertebral nerve originated at different levels from the caudal cervical ganglion (Dursun; Kalsey et al.). Our study agrees with Ozgel et al., that on both sides, the vertebral nerve originated from the craniodorsal angle of the caudal cervical ganglion, while Ozgel et al. added that it may originate from the cranioventral aspect in one cadaver. Our study agrees with Pather et al. and Ozgel et al., that the caudal cervical ganglion gives a branch to the brachiocephalic trunk.

Cranial to the cervicothoracic ganglion, the sympathetic nerve was divided to ansa subclavia, around the subclavian artery (Evans \& de Lahunta, 2010). In the present investigation, the left ansa subclavia was formed by the merger of the dorsal and ventral loops. The ventral loop had its origin from the caudoventral angle of the caudal cervical ganglion to merge with the dorsal loop on the lateral surface of the left subclavian artery. While the dorsal loop was originated from the caudal cervical ganglion at the caudodorsal angle below the level of first rib, the right ansa subclavia was formed by the cranial loop which originated from the cranioventral angle of the caudal cervical ganglion, then directed cranioventrally on the trachea to enter from the caudodorsal angle of the middle cervical ganglion, while the caudal loop had its origin from the cranioventral margin of the right middle cervical ganglion and directed caudoventrally, then coursed under the right subclavian artery with the vagus nerve; this loop then directed caudally on the ventral surface of trachea. Ozgel et al. in all cadavers, the ansa subclavia loop was derived from the sympathetic ganglion, while in three cadavers, ansa subclavia was formed by the union of two ventral branches ramify from the cranioventral and caudoventral aspects of the caudal cervical ganglion.

As noted in many published anatomical literatures, in general the cardiac nerve was derived from the caudal cervical ganglion and contributed in the formation of the cardiac plexus (Kalsey et al.; Ozgel et al.). In the present study, the left cardiac nerve was derived from the caudoventral angle of the caudal cervical ganglion then 
coursed caudoventrally under the left subclavian artery to unite with the right cardiac nerve near the lateral surface of trachea to form the common cardiac nerve which share in the formation of the cardiac plexus, while on the right side, the caudal cardiac nerve was derived from the caudoventral angle of the middle cervical ganglion then directed caudally on the ventrolateral surface of trachea, in addition to the caudoventral cardiac nerve which originated from the caudoventral angle of the caudal cervical ganglion.

In the previous published review of literature, there is no any anatomical publication reported the presence of the branch of the ligamentum arteriosum in the horse, except in this study, but Ozgel et al. reported it only in one donkey. Moreover, our study reported that there is a pericardial branch which was not previously reported in any published literatures.

Furthermore, sympathetic-parasympathetic communications branches were not previously reported in any literature in the horse except in the present study on both sides, but Ozgel et al. reported it on the right side in one donkey. Our findings indicate that on the left side, there is only one sympathetic-parasympathetic communication branch on the lateral surface of the esophagus, while on the right side, there are four sympathetic-parasympathetic communications branches; two from the caudal cervical ganglion and two from the middle cervical ganglion.

Finally, our findings suggest the most suitable site to produce the bilaterally caudal cervical ganglion blocks, this site between the articulation of the first and second rib, this suggestion agrees with that noted by Skarda et al. (1986). In the past, the caudal cervical ganglion blocks were performed blindly by palpating the anterior tubercle of the transverse process of the sixth cervical vertebrae but this method has a relatively high failure rate, but Abdi et al. (2004) and Feigl et al. (2007) noted that to produce the caudal cervical ganglion block, injecting either at the level sixth or seventh cervical vertebrae.

\section{CONCLUSION}

In conclusion, the present study provides anatomical information descriptions of the bilaterally cervicothoracic sympathetic system macroscopically. The left cervicothoracic sympathetic system is represented only by the caudal cervical ganglion, while the right cervicothoracic sympathetic system is represented by the caudal and middle cervical ganglion. The first record that there is a branch for ligamentum arteriosum in horse which originated from the left subclavian nerve. The first record that there are special communicating branches called sympathetic-parasympathetic communicating branches. The most suitable site of ganglion blocks from both sides; needle was placed medioventrally between the articulation of first and second rib.

\section{ACKNOWLEDGMENTS}

We are grateful to thank all staff members of Anatomy and Embryology department, Faculty of Veterinary Medicine, Alexandria University.

ABUMANDOUR, M. M. A. \& EL-DEFRAWY, F. Investigaciones morfológicas del sistema simpático cervicotorácico en el caballo (Equus ferus caballus) en Egipto. Int. J. Morphol., 34(3):923933, 2016.

RESUMEN: Doce caballos (E. ferrus caballus) adultos sanos, procedentes de Egipto, fueron disecados para realizar descripciones anatómicas macroscópicas del sistema simpático cervicotorácico bilateralmente. En el lado izquierdo, el sistema simpático cervicotorácico estuvo representado sólo por el ganglio cervical caudal, en la superficie lateral del esófago, craneal en relación a la primera costilla. En el lado derecho, el sistema simpático cervicotorácico estuvo representado por los ganglios caudal y cervical medio. El ganglio cervical caudal consistió en la fusión del octavo ganglio cervical y el primero de los tres ganglios torácicos. Se observaron ramos comunicantes entre los sistemas simpático y parasimpático; en el lado izquierdo, sólo hubo una rama presente en la superficie lateral del esófago, mientras que en el lado derecho, se observaron cuatro ramos: dos del ganglio cervical caudal y dos del ganglio cervical medio. El sitio más adecuado para la ejecución de los bloqueos ganglionares de ambos lados es a nivel medioventral, entre la articulación de la primera con la segunda costilla.

PALABRAS CLAVE: Caballo; Ganglion cervical caudal; Nervio simpático; Arteria subclavia.

\section{REFERENCES}

Abdi, S.; Zhou, Y.; Patel, N.; Saini, B. \& Nelson, J. A new and easy technique to block the stellate ganglion. Pain Physician, 7(3):327-31, 2004.

Ackerman, W. E. \& Zhang, J. M. Efficacy of stellate ganglion blockade for the management of type 1 complex regional pain syndrome. South Med. J., 99(10):1084-8, 2006. 
Arıncı, K. \& Elhan, A. Anatomi. Ankara, Kitabevi LTD, 1995.

Chung, I. H.; Oh, C. S.; Koh, K. S.; Kim, H. J.; Paik, H. C. \& Lee, D. Y. Anatomic variations of the T2 nerve root (including the nerve of Kuntz) and their implications for sympathectomy. $J$. Thorac. Cardiovasc. Surg., 123(3):498-501, 2002.

Dursun, N. Veteriner Anatomi II. Ankara, Medisan Yayınevi, 2000.

Dyce, K. M.; Sack, W. O.; Wensing, C. J. G. Textbook of Veterinary Anatomy. Philadelphia, W. B. Saunders Company, 2010.

Evans, H. E. \& de Lahunta, A. Guide to the Dissection of the Dog. $7^{\text {th }}$ ed. St. Louis (Mo.) Saunders/Elsevier, Philadelphia, 2010.

Evans, H. E. \& de Lahunta, A. Miller's Anatomy of the Dog. $4^{\text {th }} \mathrm{ed}$. Philadelphia, Saunders, 2013.

Feigl, G. C.; Rosmarin, W.; Stelzl, A.; Weninger, B. \& Likar, R. Comparison of different injectate volumes for stellate ganglion block: an anatomic and radiologic study. Reg. Anesth. Pain Med., 32(3):203-8, 2007.

Fioretto, E. T.; Guidi, W. L.; de Oliveira, P. C. \& Ribeiro, A. A. C. P. Macrostructure of the cranial cervical ganglionar complex and distal vagal ganglion during post natal development in dogs. Braz. J. Vet. Res. Anim. Sci., 40(3):197-201, 2003.

Gabella, G. The Rat Autonomic Nervous System. In: Paxinos, G. (Ed.). The Rat Nervous System. London, Elsevier Academic Press, 2004.

Hogan, Q. H. \& Erickson, S. J. MR imaging of the stellate ganglion: normal appearance. A. J. R. Am. J. Roentgenol., 158(3):655-9, 1992.

Kalsey, G.; Mukherjee, R. N. \& Patnaik, V. V. G. A comparative study of cervical sympathetic chain. J. Anat. Soc. India, 49(1):26-30, 2000.

Katritsis, E. D.; Lykaki-Anastopoulou, G. \& Papadopoulos, N. J. The relations of the superior pole of the stellate ganglion to the vertebral artery. Anat. Anz., 150(3):259-63, 1981.

König, H. E. \& Liebich, H. G. Veterinary Anatomy of Domestic Mammals. Textbook and Colour Atlas. $4^{\text {th }}$ ed. Holderlinstrabe, Schattauer, 2007.

Marcer, N.; Bergmann, M.; Klie, A.; Moor, B. \& Djonov, V. An anatomical investigation of the cervicothoracic ganglion. Clin. Anat., 25(4):444-51, 2011.

Ozgel, O.; Duzler, A.; Dursun, N. \& Beyaz, F. The morphology of the cervico-thoracic sympathetic system in donkeys (Equus asinus L.). Anat. Histol. Embryol., 38(2):139-44, 2009.

Pather, N.; Partab, P.; Singh, B. \& Satyapal, K. S. Cervico-thoracic ganglion: its clinical implications. Clin. Anat., 19(4):323-6, 2006.
Phillips, J. G.; Randall, W. C. \& Armour, J. A. Functional anatomy of the major cardiac nerves in cats. Anat. Rec., 214(4):365-71, 1986.

Raj, P. P. Stellate Ganglion Block. In: Waldman, S. D. \& Winnie, A. P. (Eds.). Interventional Pain Management. Philadelphia, Saunders, 1996.

Rosse, C. \& Gaddum-Rosse, P. Hollinshead's Textbook of Anatomy. $5^{\text {th }}$ ed. Philadelphia, Lippincott-Raven Publishers, 1997. pp.728-9.

Schürmann, M.; Gradl, G.; Wizgal, I.; Tutic, M.; Moser, C.; Azad, S. \& Beyer, A. Clinical and physiologic evaluation of stellate ganglion blockade for complex regional pain syndrome type I. Clin. J. Pain, 17(1):94-100, 2001.

Singh, B.; Ramsaroop, L.; Partab, P.; Moodley, J. \& Satyapal, K.vS. Anatomical variations of the second thoracic ganglion. Surg. Radiol. Anat., 27(2):119-22, 2005.

Skarda, R. T.; Muir, W.W.; Swanson, C. R. \& Hubbell, J. A. Cervicothoracic (stellate) ganglion block in conscious horses. Am. J. Vet. Res., 47(1):21-6, 1986.

Correspondence to:

Mohamed M. A. Abumandour

Assistantn Professor of Anatomy and Embryology

Faculty of Veterinary Medicine

Alexandria University

Anatomy and Embryology department

Faculty of Veterinary Medicine

Rashid, Edfina, Behera

EGYPT

Post Box: 22785

Mob. +201000322937

Fax: +20452960450

Email: m.abumandour@yahoo.com

Received: 07-11-2015

Accepted: 15-04-2016 